\title{
Evaluation of Costus speciosus in Experimental Models of Depression in Albino Mice
}

\author{
Zahoor Ahmad Rather', Nateshprabhu M², Sushma DS³, Rakesh Kb', Sunil Pai' , Ullal Sheetal D ${ }^{\text {* }}$ \\ 'Department of Pharmacology, Kasturba Medical College, Mangalore, Manipal University, Karnataka, INDIA. \\ 2Department of Pharmacology, Dhanalakshmi Srinivasan Medical College and Hospital, Perambalur, TamilNadu, INDIA. \\ 3Department of Pharmacology, Khaja Banda nawaz Institute of Medical Sciences, Kalburgi Karnataka, INDIA.
}

\begin{abstract}
Introduction: Despite theavailability of numerous antidepressant drugs the therapy of depression is far from satisfactory. Two of the many reasons for this are the delay in onset of effect and the adverse effects associated with most of the antidepressants. Costus speciosus rhizome has shown adaptogenic activity. Objective: To evaluate the antidepressant activity of $50 \%$ aqueous-ethanol extract of Costus speciosus (CS) leaves in experimental models of depression. Materials and Methods: Male albino mice were randomly assigned to five groups of six each. We studied three doses of the leaf extract $(100,200$ and $400 \mathrm{mg} / \mathrm{kg})$ on two models of depression - forced swim test and tail suspension test. Imipramine was used as the standard control. Both acute and chronic effects were studied. Drugs (test drug, standard control and vehicle) were administeredorally, one hour before the experiment in the acute study and daily for 14 days for the chronic study. Results: Imipramine showed significant antidepressant activity as demonstrated by a reduction in duration of immobility in both acute and chronic studies of forced swim test and tail suspension test. CS showed a dose dependent antidepressant activity. CS_100 demonstrated an antide-
\end{abstract}

pressant effect only in the acute forced swim test. CS_200 demonstrated an antidepressant activity in both acute and chronic forced swim test but not in tail suspension test. CS_400 showed maximum antidepressant activity in both acute and chronic studies, which was comparable to that of the standard drug imipramine. Conclusion: CS showed dose dependent antidepressant activity with CS_400 mg/kg showing maximum effect.

Key words: Antidepressant, Costus speciosus, Forced swim test, Tail suspension, Test.

Corresponding author: Ullal Sheetal D, Associate Professor, Department of Pharmacology, Kasturba Medical College, Mangalore, Manipal University, Karnataka, INDIA.

Phone no: 9448306242

Email: sheetal.ullal@manipal.edu

DOI : $10.5530 /$ pj.2016.5.12

\section{INTRODUCTION}

Depression is a heterogeneous disorder that affects a person's mood, physical health and behaviour. The signs and symptoms include guilt, loss of interest, disturbed sleep or appetite, aches, fatigue, poor concentration and suicidal tendency. Depression affects 121 million people worldwide leading to a suicide rate of 850,000 lives every year and predicted to be the second leading cause of death by $2020 .{ }^{1}$ Despite progress in pharmacotherapy, in a majority of patients,depression goes undiagnosed and untreated or unsatisfactorily treated. ${ }^{2}$ The delayed onset of action of antidepressants and their adverse effectsrenders it necessary to find newer and safer therapeutic agents which would complement the existing treatment modalities. ${ }^{3}$ Therefore, it is worthwhile to explore the utility of traditional medicines for the treatment of various depressive disorders.

Costus speciosus (CS) rhizome has been proven to show anti-diabetic, anti-dyslipidemic, ${ }^{4}$ hepatoprotective, ${ }^{5}$ adaptogenic,${ }^{6}$ anti-bacterial, ${ }^{7}$ antifertility, ${ }^{8}$ anti-inflammatory, anti-pyretic, ${ }^{9}$ and estrogenic ${ }^{10}$ activity. Therootsof CShave also been proven to contain antihyperglycemic, hypolipidemic and anti-oxidant ${ }^{11}$ properties. But its leaves have not been studied extensively and have only shown anti-oxidant ${ }^{12}$ activity.

There is no literature evidence demonstrating the effect of aqueousethanol extract of leaves of Costus speciosus on depression models. Hence this study was conducted to evaluate the antidepressant activity of $50 \%$ aqueous-ethanol extract of Costus speciosus leaves in two experimental models of depression in mice.

\section{MATERIALS AND METHODS}

Animals: Male albino mice weighing 25-40 g inbred in the institutional animal house were used for the study. Mice were housed in clean polypropylene cages, three mice in each cage, in a controlled environment $\left(22^{\circ}-24^{\circ} \mathrm{C}\right)$ with a $12 \mathrm{hr}$ light and dark cycle with standard chow containing fat $4.15 \%$, protein $22.15 \%$, carbohydrates $4 \%$ (supplied by Amruth laboratory animal feed, manufactured by Pranav Agro industries Ltd., Sangli) and water ad libitum. The study animals were allowed to acclimatise to these conditions for one week. Experiments were performed during the light phase of the cycle (10:00-17:00).

\section{Drugs and Chemicals}

Preparation of Costus speciosus leaves extract (Study Drug): Leaves were collected from the plants growing in Dakshina Kannada district, Karnataka State, in the months of September and shade dried. The aqueous ethanol extract was prepared by using soxhlet apparatus (50\% ethanol at $\left.55^{\circ} \mathrm{C}\right)$.

Standard drug: Imipramine at the dose of $10 \mathrm{mg} / \mathrm{kg}$, orally (suspended in $1 \%$ gum acacia). ${ }^{13}$

Study Procedure: Mice were randomly assigned to five groups of six mice each. The feeding and treatment schedule was as follows:

Group 1: Distilled water (Normal control)orally

Group 2: Imipramine $10 \mathrm{mg} / \mathrm{kg}$ orally (suspended in $2 \%$ gum acacia).

Group 3: CS leaves (50\% aqueous-ethanol extract) dissolved in distilled water orally $100 \mathrm{mg} / \mathrm{kg}$

Group 4: CS leaves (50\% aqueous-ethanol extract)dissolved in distilled water orally $200 \mathrm{mg} / \mathrm{kg}$

Group 5: CS leaves (50\% aqueous-ethanol extract) dissolved in distilled water orally $400 \mathrm{mg} / \mathrm{kg}$

The study was conducted in two phases - acute and chronic. Drugs (test drug, standard control and vehicle) wereadministered one hour before 
Table 1: Forced swim test

\begin{tabular}{ccc}
\hline Groups & $\begin{array}{c}\text { Acute forced swim test (FST) } \\
\text { immobility in seconds }\end{array}$ & $\begin{array}{c}\text { Chronic forced swim test (FST) } \\
\text { immobility in seconds }\end{array}$ \\
\hline Normal control & $128 \pm 17.24$ & $129.00 \pm 16.62$ \\
Imipramine $10 \mathrm{mg} / \mathrm{kg}$ & $70.83 \pm 7.81^{*}$ & $75.00 \pm 7.56^{*}$ \\
Costus speciosus $100 \mathrm{mg} / \mathrm{kg}$ & $92.67 \pm 4.5^{\star *}$ & $106.83 \pm 7.93^{*}$ \\
Costus speciosus $200 \mathrm{mg} / \mathrm{kg}$ & $83.33 \pm 13.8^{*}$ & $98.33 \pm 13.5^{*}$ \\
Costus speciosus $400 \mathrm{mg} / \mathrm{kg}$ & $80.17 \pm 15.1^{*}$ & $91.17 \pm 15.8^{*}$ \\
\hline
\end{tabular}

${ }^{*} \mathrm{P}<0.05$ compared with normal control; $\# \mathrm{P}<0.05$ compared with imipramine

All values are expressed as Mean \pm SD

Original

Table 2: Tail suspension test

\begin{tabular}{ccc} 
Groups & $\begin{array}{c}\text { Acute tail suspension test immobility } \\
\text { in seconds }\end{array}$ & $\begin{array}{c}\text { Chronic tail suspension test immobility } \\
\text { in seconds }\end{array}$ \\
\hline Normal control & $275.50 \pm 24.28$ & $276.17 \pm 25.29$ \\
Imipramine $10 \mathrm{mg} / \mathrm{kg}$ & $207.00 \pm 17.10^{*}$ & $205.50 \pm 11.59^{*}$ \\
Costus speciosus $100 \mathrm{mg} / \mathrm{kg}$ & $242.50 \pm 14.30^{*}$ & $242.17 \pm 15.57^{*}$ \\
Costus speciosus $200 \mathrm{mg} / \mathrm{kg}$ & $234.00 \pm 11.86$ & $233.00 \pm 12.96^{*}$ \\
Costus speciosus $400 \mathrm{mg} / \mathrm{kg}$ & $228.50 \pm 16.56^{*}$ & $222.83 \pm 14.91^{*}$ \\
\hline
\end{tabular}

${ }^{\star} \mathrm{P}$ value $<0.05$ compared with normal control; \#P value $<0.05$ compared with imipramine.

All values are expressed as Mean \pm SD

Original

the experiment in the acute study whereas for the chronic studydrugs were given daily for 14 days.

\section{Animal models for testing antidepressant activity: ${ }^{14}$}

A) Forced swim test (Porsolt test): ${ }^{15}$ This animal model is based on the principle that forcing mice to swim in a restricted space from which they cannot escape leads to a characteristic behaviour of immobility. This behaviour reflects a state of despair, which can be reduced by several agents that are therapeutically effective in human depression.

Mice were individually forced to swim inside a vertical plexiglass cylinder (height $50 \mathrm{~cm}$, diameter $20 \mathrm{~cm}$ ) containing a water column of $15 \mathrm{~cm}$ height. After an initial two minute period of vigorous activity, usually each animal assumes a typical immobile posture. A mouse was considered immobile when it remained floating in the water without struggling, making only minimum movements of its limbs necessary to keep its head above water. The duration of immobility was recorded during the latter 4 minutes of the total six minutes of the duration of the test. Duration of immobility was compared with that of controls.

B) Tail Suspension Test in Mice: ${ }^{16}$ This test is a variant of the behavioural despair test in which immobility is induced by simply suspending a mouse by its tail. This test is a reliable and rapid screening method for antidepressants, including those involving serotonergic system. This animal model is based on the principle that suspending mice upside down leads to a characteristic behaviour of immobility after initial momentary struggle. This behaviour reflects a state of despair which can be reduced by several agents which are therapeutically effective in human depression. In the acute study, this test was performed one hour after drug administration and in the chronic studyone hour after drug administration on day 14.

Mice were suspended on a metal rod stand $70 \mathrm{~cm}$ above the table top by an adhesive tape placed approximately $1 \mathrm{~cm}$ from the tip of the tail. Immobility time was recorded during the latter $6 \mathrm{~min}$ of the total
8 min duration of the test. The animal was considered immobile when it did not show any movement of body and hanged passively.

Ethical Issues: The study was approved by the Institutional Animal Ethics Committee (IAEC) and was conducted according to the guidelines laid down by the CPCSEA.

Statistical Analysis: All results are expressed as Mean \pm SD. All the groups wereanalysed using one way ANOVA followed by Dunnett test.

\section{RESULTS}

As shown in Table 1 there is a decrease in the duration of immobility in all the treated groups compared to control in both acute as well as chronic studies, except Costus speciosus 100 (CS_100) group which did not show any difference compared to the normal control in the chronic study. There was a significant reduction in duration of immobility in the imipramine treated group in both acute and the chronic studies $(\mathrm{p}=0.001)$. There also was a significant reduction in duration of immobility in all the CS treated groups in the acute study but in the chronic study CS_100 did not show any significant reduction in duration of immobility $(\mathrm{p}=0.145)$. In the acute study the duration of immobility in the CS_100 group was significantly less than the normal control $(\mathrm{p}=0.024)$ but also significantly more than the imipramine treated group $(\mathrm{p}=0.003)$. In the acute study both CS_200 and 400 did not show any significant difference with the imipramine group ( $\mathrm{p}=0.499$ and 0.831 respectively), while in the chronic study only CS_400 did not show any significant difference with the imipramine group $(\mathrm{p}=0.346)$.

As shown in table 2 in the acute study using tail suspension test there was a significant reduction in duration of immobility in the imipramine $(\mathrm{p}=0.003)$ and CS_400 groups $(\mathrm{p}=0.031)$ compared to normal control. There was no significant difference between the imipramine and CS_400 groups ( $\mathrm{p}=0.339$ ). In the chronic study using tail suspension test imipramine as well as CS_400 significantly reduced duration of immobility ( $\mathrm{p}=0.004$ and 0.017 respectively). CS_100 and 200 groups showed no significant difference in the duration of immobility compared to normal 
control group ( $\mathrm{p}=0.159$ and 0.051 respectively). There was no significant difference between the imipramine and CS_400 groups $(\mathrm{p}=0.327)$.

\section{DISCUSSION}

The effects of leaves of Costus speciosus on the central nervous system has not yet been studied though the plant has shown to have antioxidant effects. Hence we decided to start with evaluating the antidepressant activity of aqueous ethanol extract of Costus speciosus leaves in experimental models of depression. We studied three doses of the leaf extract $(100,200$ and $400 \mathrm{mg} / \mathrm{kg})$ on two established models of depression in mice - forced swim test and tail suspension test. Imipramine, an antidepressant drug was used as a standard control. Both acute and chronic effects of the test drug were studied.

As expected, imipramine showed significant antidepressant activity as demonstrated by a reduction in duration of immobility in both acute and chronic studies of forced swim test and tail suspension test. Costus speciosus showed a dose dependent antidepressant activity. CS_100 demonstrated an antidepressant effect in the acute forced swim test but not in the chronic forced swim test. Moreover in the acute forced swim test the antidepressant effect of CS_100 was less than that of imipramine. In the tail suspension test CS_100 did not show any antidepressant effect. CS_200 demonstrated an antidepressant activity in both acute and chronic forced swim test. In the acute study, the effect of CS_200 was equivalent to that of imipramine but its efficacy reduced on chronic administration as has been shown in the significantly higher duration of immobility compared to imipramine. In the tail suspension test CS_200 did not show any antidepressant activity. CS_400 showed maximum antidepressant activity among all the doses of CS administered in both acute and chronic studies. This antidepressant effect of CS_400 was comparable to that of the standard drug imipramine. CS_100 and 200 showed antidepressant activity only in acute studies of the forced swim test but not on chronic administration. This could be because of development of tolerance on repeated administration; however the mechanism of antidepressant activity of CS and its proposed development of tolerance was not assessed in this study and could be planned in future studies.

\section{CONCLUSION}

Costus speciosus showed dose dependent antidepressant activity with the dose of $400 \mathrm{mg} / \mathrm{kg}$ showing maximum effect.

\section{ACKNOWLEDGEMENT}

None.

\section{CONFLICT OF INTEREST}

The author declare no conflict of interest.

\section{ABBREVIATION USED}

CS: Costus speciosus; SD: Standard Deviation; ANOVA: Analysis of Variance; CPCSEA: Committee for the Purpose of Control and Supervision of Experiments on Animals.

\section{REFERENCES}

1. Kessler RC, Berglund P, Demler O, Jin R, Merikangas KR, Walters EE. Lifetime prevalence and age-of-onset distributions of DSM-IV disorders in the National Comorbidity Survey Replication. Arch Gen Psychiatry. 2005;62(6):593-602.

2. Gold PW, Goodwin FK. Clinical and biochemical manifestations of depression in relation to the neurobiology stress: Part 1.N Engl J Med. 1988;319(6):348-53

3. Rosenzweig-Lipson S, Beyer CE, Hughes ZA, Khawaja X, Rajarao SJ, Malberg JE et al. Differentiating antidepressants of the future: Efficacy and safety. Pharmacol Thera. 2007;113(1):134-53

4. Eliza J, Daisy P, Ignacimuthu S, Duraipandiyan V, Antidiabetic and antilipidemic effect of eremanthin from Costus speciosus (Koen.)Sm., in STZ-induced diabetic rats. Chemico-biological Interactions. 2009;182(1):67-72.

5. NitinVerma and Khosa RL. Evaluation of protective effects of ethanolic extract of Costus speciosus (Koeing).sm rhizome on carbon tetrachloride induced hepatotoxicity in rats. Natural Product Radiance. 2009;82(3):123-26.

6. Verma $\mathrm{N}$ and Khosa RL. Effect of Costus speciosus and Wedeliachinensis on Brain Neurotransmitters and Enzyme Monoamine Oxidase Following Cold Immobilization Stress. J Pharm Sci \& Res. 2009;1(2):22-5

7. Malabadi R.B. Antibacterial activity in the rhizome extracts of Costus speciosus (Koen). J Phytol Res. 2005;18(1):83-5.

8. Tewari PV, Chaturvedi C, Pandey VB. Antifertility activity of Costus speciosus. Indian Journal of Pharmacy. 1973;35(4):114-5.

9. Binny, Kumar SG and Thomas D. Anti-inflammatory and antipyretic properties of the rhizome of Costus speciosus (Koen.) sm. Journal of Basic and Clinical Pharmacy. 2010;1(3):177-81.

10. Singh S, Sanyal AK, Bhattacharya SK, Pandey VB. Estrogenic activity of saponins from Costus speciosus (Koen) Sm. Indian Journal of Medical Research. 1972;60(2):287-90.

11. Bavarva JH, Narasimhacharya AV. Antihyperglycemic and hypolipidemic effects of Costus speciosus in alloxan induced diabetic rats. Phytother Res. 2008;22(5):620-6.

12. Chakraborthy GS. Free radical scavening activity of Costus speciosus leaves Indian J Pharm Educ Res. Cooke DW. Diabetes. In: Encyclopaedia of Biological Chemistry. 2009;43(1):96-8.

13. Seema R, Mukta NC, Natesh PM, Nishchal BS, Yogesh B, Nishith RS. Evaluation of Tribulus Terrestris in Depression Models of Albino Mice. Am J Pharm Tech Res. 2013;3(1):538-46.

14. Gupta SK. Anti-depressant agents. In: Drug screening Methods. $2^{\text {nd }}$ ed. New Delhi: Jaypee publishers. 2008;392-9.

15. Porsolt RD, Bertin A, Blavet N. Immobility induced by forced swimming in rats: effects of agents which modify central catecholamine and serotonin activity. Eur J Pharmaco. 1979;57(2):201-10.

16. Chermat R, Thierry B, Mico JA. Adaptation of the tail suspension test to the rat. J Pharmacol. 1986;17(3):348-50. 
PICTORIAL ABSTRACT

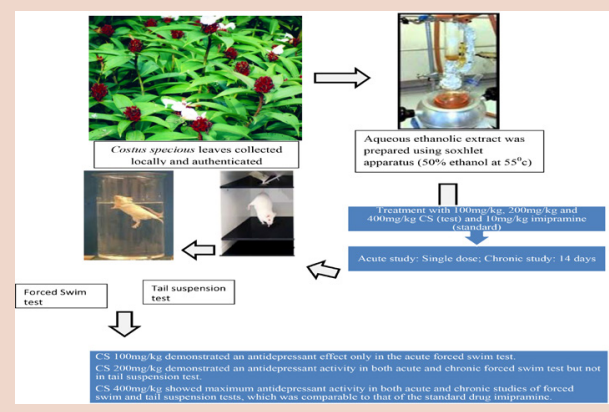

\section{SUMMARY}

- Study evaluated the antidepressant activity of $50 \%$ aqueous-ethanol extract of Costus speciosus (CS) leaves in two experimental models of depression in mice.

- Three doses of the leaf extract (100, 200 and $400 \mathrm{mg} / \mathrm{kg}$ ) on two models of depression - forced swim test and tail suspension test were studied. Both acute and chronic effects were studied.

- Costus speciosus showed a dose dependent antidepressant activity. CS $100 \mathrm{mg} / \mathrm{kg}$ demonstrated an antidepressant effect only in the acute forced swim test. CS $200 \mathrm{mg} / \mathrm{kg}$ demonstrated an antidepressant activity in both acute and chronic forced swim test but not in tail suspension test. CS $400 \mathrm{mg} / \mathrm{kg}$ showed maximum antidepressant activity in both acute and chronic studies of forced swim and tail suspension tests, which was comparable to that of the standard drug imipramine.

- Costus speciosus showed dose dependent antidepressant activity with CS_400 mg/kg showing maximum effect.

\section{ABOUT AUTHORS}

Zahoor Ahmad Rather: Is a tutor and research scholar at the Department of Pharmacology, Kasturba Medical College, Mangalore. He is pursuing his doctoral research at Manipal University. His is mainly focused on brain research in animals.

Dr Sheetal D Ullal: Completed her MD in Pharmacology from Manipal University in 2002. Presently, she is an Associate professor in the Department of Pharmacology, Kasturba Medical College, Mangalore, Manipal University. Her areas of interest are preclinical research in inflammation and diabetes, medical education and bioethics. 